\title{
MANAGING IT INNOVATION: RECESSIONARY AND POST-RECESSIONARY SERVICE AND STAFFING MODELS
}

\author{
Joseph M. Woodside ${ }^{1}$ \\ ${ }^{1}$ Department of Decision and Information Sciences, Stetson University, US
}

\begin{abstract}
Information Technology (IT) service and staffing models were increasingly reduced in the wake of recession, which often limits focus for long-term innovation, as the remaining services and staff are focused on producing short-term requirements. Despite these cutbacks, organizations must continue to innovate and provide contributions to the set of stakeholders. In addition as the post-recessionary timeframe begins, organizations that continued to innovate throughout the recession, must retain human capital and take advantage of their prior investments. Organizations that focus on innovation during recessionary timeframes, are more likely to emerge in a superior competitive position during post-recessionary timeframes. This paper explores identified industry best practices for IT service and staffing models that can be utilized to ensure adequate resources are dedicated to achieving innovation, and management implications for post-recessionary methods. In addition, a review of the capacities and capabilities which fall under the new IT service and staffing models are developed in the form of an innovation matrix. This approach reduces IT requirements to focus on key strategic service areas, with considerations for reduced staffing needs during periods of economic downturn, and staffing retention during the following economic upturn.
\end{abstract}

\section{KEYWORDS}

Management, Information Technology, Innovation, Recession, Post-Recession, Service, Staffing

\section{INTRODUCTION AND SIGNIFICANCE}

During the previous periods of financial crisis and recession, companies experienced significant IT cut-backs. In a recent Robert Half Technology survey, nearly two-thirds of CIOs identified IT staffing as a limiting factor in deploying new and innovate technologies [1]. IT management must meet the current demands of users, while supporting increased customer growth and innovation, all with budgets unchanged or reduced [2].

In the lean business environments of today, ongoing short-term requirements absorb the majority of the bandwidth from executives, managers, and professional workers. Organizations are too busy responding to immediate customers, that limited time is spent towards improvements within the organization, thereby restraining organizational evolution. When spending constraints and alternative investments are evaluated, competition for resources is high. Organizations then often choose to make minor incremental investments vs. major investments in a few strategic areas. 
This typically results in initiatives proceeding more slowly and delivering lower value, which results in negative viewpoints of information systems investments [3].

Despite the challenges, leading companies are dedicating funding for innovation despite the recession, and the recessionary timeframe may in fact be a good period for aggressive growth [4]. Innovation can be fostered by aligning IT budgets for strategic technology initiatives with revenue and business objectives. Transforming IT from a cost to profit center requires going beyond keeping the lights on, and supporting business needs and growth [2]. This paper presents an identified framework aimed at supporting innovation through improved IT service and staffing models during and after recessionary periods [5].

\section{FRAMEWORK FOR IT SERVICE AND STAFFING ALLOCATIONS}

The resource-based view of the firm is based on the idea that valuable resources are the key to competitive advantage. Dynamic capabilities extend the resource-based view of the firm by incorporating changing environmental factors. Dynamic resources allow a firm to quickly adapt to changing requirements, and adjust their resources accordingly, to sustain a competitive advantage. These findings suggest that IT resources are a critical component to a firm's competitiveness. Strategy and resource allocation are similar, in that strategy can be seen as cyclical process for how best to allocate resources $[6,7]$.

The following section presents identified industry best practices for IT service and staffing allocations, to promote innovation within a given organization. Many of these practices have shifted more quickly as a result of the recent recession, and requires companies to focus on strategies which will allow the organization to remain sustainable in the short and long-term. As a result, many service and staffing models are being transformed, allowing successful companies to continue to innovate in the downturn. Table 1 displays the common operating state of organizations, and the desired state to drive innovation as generated from within the following best practice sections. Specifically these areas include establishing a service catalog, optimizing the application services portfolio, aligning service oriented architectures, assigning staffing allocations, identifying emerging services, and generating sustainability.

\subsection{Establish Service Catalog}

Effective IT service management involves establishing cost effective and efficient services, which can be addressed through an IT service catalog. The service catalog provides a tool for communicating and visualizing IT business components, and allows planning, measuring, and management. Services may include servers, applications, people, or licenses [8].

Common steps to developing a service catalog include: Develop the types of services provided, develop the service level agreements, develop performance objectives, establish methods for service and performance monitoring, establish service management staff, deploy service catalog to end-users, and continually improve service catalog [9]. 


\subsection{Optimize Application Services Portfolio}

Organizations today often run hundreds of information systems and applications that support business processes. Applications are historically the main products that IT delivers to the customer, and are increasing shifting to services [10]. Few organizations have a defined an applications and services portfolio strategy, and increasingly spend more time and budget (as high as $80 \%$ or more) on maintaining and supporting existing systems. These applications and services may include email, business intelligence, ERP, and financial. For portfolio management maturity, organizations move from no portfolio management, to basic improvement projects and definition of portfolio, to transformation where a defined and aligned roadmap exists between business and IT, to business led governance and strategy for organizational benefits. The portfolio must then be further optimized from a cost of management and maintenance standpoint, and from a strategic perspective to deliver increasing business value [11].

\subsection{Align Service Oriented Architecture}

Systems of record are the required applications for core business functions, such as financial or transaction-based systems. These systems are typically on-premise systems, slow to change, and span decades of operation. Systems of differentiation improve agility and utilize existing information for competitive purposes. These systems are collaborative and typically require support spanning a few years, with a mix on on-premise and cloud-based systems delivery. Systems of transformation are driven by and drive the business, and typically have short support times, and are well-matched to cloud-based systems delivery [12].

\subsection{Identify Emerging Services}

The IT services market was over $\$ 450$ billion in 2010 , and will continue to change with the introduction of cloud-based and SaaS technologies. In light of the economic downturn, IT service models will change, driving lower cost solutions and strategies. Many organizations are updating their IT expenditures from capital expenditures to operating expenditures, which is fueling the change from applications to pay as you go services. Traditional services such as IT consulting, system integration, and outsourcing, will be replaced by emerging services such as security-as-aservice, BI-as-a-service, SaaS, PaaS, services, and cloud services [11, 13].

\subsection{Generate Sustainability}

IT sustainability or green IT, involves developing technologies, infrastructure, and business models that result in reduced emissions, costs, and lower environmental impact. For example, datacenter consolidation, virtualization, and efficiency improvements are examples of sustainable IT $[14,15]$.

While recession may modify short-term priorities, an economic downturn shouldn't derail a longterm sustainability strategy, as the issues of sustainability will remain after the recession ends. Climate change, society's environmental knowledge, and data increases, have required environmental intelligence as a component of business intelligence, which promises IT driven business improvements through sustainability, efficiency, and competiveness [16]. 
The main areas of sustainability include regulation, stakeholder interest, cost reduction, and new business. Regulation involves the basic requirements and associated penalties, such as emission or climate change laws. Stakeholder interest is pressure or influence from employees, customers, or shareholders to move an organization in a short-term direction. Cost reduction is the balancing of environmental and financial requirements. For example, most organizational servers waste energy as they only utilize six percent of available capacity; improvements here can reduce energy costs while also reducing the carbon footprint. New business involves identifying services that will result from a sustainability strategy, such as RFID, carbon-monitoring software, and energy efficient technologies [16].

Table 1: Service and Staffing States for Innovation

\begin{tabular}{|l|l|}
\hline $\begin{array}{l}\text { IT Service and Staffing Models Common } \\
\text { State }\end{array}$ & $\begin{array}{l}\text { IT Service and Staffing Models for } \\
\text { Innovation }\end{array}$ \\
\hline $\begin{array}{l}\text { IT services and costs vary and are } \\
\text { undocumented; operate in reactive mode }\end{array}$ & $\begin{array}{l}\text { IT services and costs defined and } \\
\text { communicated through service catalog; } \\
\text { services optimized }\end{array}$ \\
\hline Basic application portfolio management & $\begin{array}{l}\text { Services portfolio management, optimization, } \\
\text { and transformation }\end{array}$ \\
\hline $\begin{array}{l}\text { Own entire infrastructure; service delivery on } \\
\text { premise }\end{array}$ & $\begin{array}{l}\text { Shared / outsourced infrastructure (SaaS; } \\
\text { IaaS, PaaS); service delivery on demand }\end{array}$ \\
\hline $\begin{array}{l}\text { Majority of staffing time spent on keeping } \\
\text { the lights on }\end{array}$ & $\begin{array}{l}\text { Majority of staffing time dedicated for } \\
\text { innovation and projects }\end{array}$ \\
\hline $\begin{array}{l}\text { IT focused support on systems of record; } \\
\text { legacy services pursued }\end{array}$ & $\begin{array}{l}\text { IT focused support on systems of } \\
\text { differentiation and transformation; emerging } \\
\text { services pursued }\end{array}$ \\
\hline Regulation based sustainability compliance & New business strategy for sustainability \\
\hline $\begin{array}{l}\text { Value measured by incident volume / } \\
\text { customer satisfaction }\end{array}$ & $\begin{array}{l}\text { Value measured by organizational growth and } \\
\text { innovation }\end{array}$ \\
\hline
\end{tabular}

\section{IT SERVICE AND STAFFING ALLOCATIONS FOR INNOVATION}

Martensson (2006) introduces a resource allocation matrix, which is divided into short-term and long-term perspectives, and obligation and opportunity items, for a total of four initiatives: FireFighting, Platform Construction, Agile Action, and Business Transformation. Firefighting is a short-term perspective and is a reactive mode intended to solve problems. Agile action takes advantage of short-term opportunities, such as a first mover advantage, and requires existing flexible systems. Platform construction is a long-term proactive perspective that resolves rootcause and long-term issues. Lastly, business transformation is a long-term perspective for future business opportunities. The resource allocation matrix can be utilized to monitor existing IT usage, and create transparent resource allocation. The allocation percentages may vary by organization depending on strategy and particular state. The matrix can also assist with showing 
IT resources participating in both short-term and long-term perspectives and where resources are currently spent [7].

In line with the long-term perspective of pursuing opportunities, leading innovators such as $3 \mathrm{M}$ and Google offer dedicated time for employees to work on personal projects. 3M offers a 15 percent rule, while Google offers a 20 percent rule, and both have had significant products developed through this approach such as post-its, masking tape, G-Mail, and AdSense. The common thread is that this concept is deeply embedded in the culture and attitudes of the companies, and rely on the special projects to help drive future growth [17-19].

Extending Martensson's(2006) resource allocation matrix, an IT service and staffing allocation matrix for innovation is displayed in Figure 1. The matrix is developed and presented with identified components corresponding to the industry best practices. The matrix includes both short-term and long-term focused items, as well as pursuing opportunities and meeting requirements. For each identified industry best practice, the components are categorized within the appropriate block. This allows an organization to identify key gaps while moving from 'firefighting' and 'keeping the lights' on to business transformation. A common allocation for a company today, in a recessionary service and staffing model may be $80 \%+$ of IT staff time spend on short-term requirements needs, leaving little time for long-term innovative needs. Whereas other companies may ensure 20\%+ of IT staff time is dedicated to long-term business transformation and innovation needs.

While the ongoing allocations may change or vary from organization to organization, the key will be to maximize innovation strategies and minimize support and maintenance strategies to survive during the economic downturn after the economic upturn. Organizations that continue their focus on innovation during the downturn, are more likely to emerge and position themselves for further growth than competitors who have reduced or eliminated long-term service and staffing allocations.

\begin{tabular}{|c|c|c|}
\hline & Short Term Focus & Long Term Focus \\
\hline $\begin{array}{c}\text { Pursuing } \\
\text { Opportunities }\end{array}$ & $\begin{array}{l}\text { Agile Action } \\
\text { - } \quad \text { IT Services Operate in Proactive Mode } \\
\text { - Services Portfolio Management Existing } \\
\text { - Spportunities } \\
\text { - Service Delivery On Premise \& On } \\
\text { - Enterprise Systems of Differentiation } \\
\text { - Staffing Time Dedicated for Opportunity } \\
\text { - } \quad \text { Projects } \\
\text { - Smerging Services Opportunities Pursued } \\
\end{array}$ & $\begin{array}{l}\quad \text { Business Transformation } \\
\text { - IT Services Optimized } \\
\text { - Services Portfolio Management } \\
\text { Transformation } \\
\text { - Service Delivery On Demand } \\
\text { - Staffing Time Dystems of Transformation } \\
\text { Projects } \\
\text { - Emerging Services Pursued } \\
\text { - New business strategy for sustainability } \\
\end{array}$ \\
\hline $\begin{array}{c}\text { Meeting } \\
\text { Requirements }\end{array}$ & 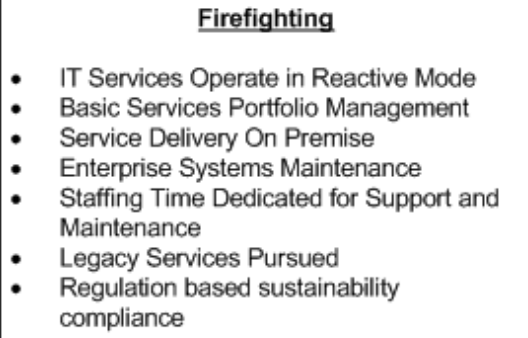 & $\begin{array}{l}\quad \text { Platform Construction } \\
\text { - } \\
\text { - Services Portfolio Management } \\
\text { - } \text { Seveloped } \\
\text { - } \quad \text { Entervice Delivery On Premise Systems of Record } \\
\text { - Staffing Time Dedicated for Planned } \\
\text { Projects } \\
\text { - Legacy Services Upgrade Path } \\
\text { - Cost reduction sustainability }\end{array}$ \\
\hline
\end{tabular}

Figure 1: IT Service and Staffing Allocation Matrix for Innovation 


\section{MANAGEMENT IMPLICATIONS DISCUSSION}

The staffing and benefit cuts enacted during the recession, have resulted in reducing employee engagement, leaving workers feeling undervalued. Despite the technical recovery period in the US, overall median annual income declined nearly 5 percent from 2009 - 2012, with individual groups faring better or worse during the post-recessionary recovery period [20, 21]. As the economy improves, businesses are facing increasing challenges with employee engagement and retention. Due to organizations asking employees to take financial cuts, and increased workloads during the recession, employees are now looking to be rewarded as the economy and financial status of the organization improves. In a recent survey, nearly $60 \%$ of workers intended on seeking new employment as the economy continues to improve. The remainder of employees are also updating resumes, networking for potential new opportunities, or plan to stay in their current position. While it is important to move forward with innovation, employees are the key to improving results $[20,22]$. The following sections describes management methods during the post-recessionary period in order to reestablish relationships with employees, monitor employee fatigue and burn out, keep employees engaged and retained, while continuing to develop talent and innovation.

\subsection{Re-establishing Trust}

Within the past and current environment of uncertainty and instability, employees value leaders who care about them, empathize with them, and can connect emotionally with them, with trustworthiness as a key theme. In one survey, job security and job stability were the key themes for employees, ahead of common items such as career advancement and job satisfaction. $80 \%$ of respondents indicated that they were looking for a long-term position, staying in one or at most three companies their entire career. This is much different than the free-agent employment in the prior decade. Managers must regain employee trust and build competitive organizations with a culture of trust and reputation. Changes will be required from recessionary periods due to the workforce experience with reduced staffing, benefits, and retirement reductions [22-24].

\subsection{Relationship Building}

One the greatest factors in employee retention is the employee relationship with their direct manager, with $94 \%$ intending to stay with a manager who cared about their well-being. These relationships cannot be left alone and must be continually developed with each employee and manager. As a manager, it is important to give ongoing feedback such as in weekly one on one meetings, instead of waiting for annual performance periods. Start coaching with direct timely feedback to each employee to ensure goals are successfully completed. The organization should also challenge managers and employees to continuously improve. Growth organizations have accessible, empowering, trusting managers. Nearly half of declining organizations had authoritarian management styles. Management styles were found to lead to engagement, job satisfaction, mental and physical health, productivity, and business success [22-24].

\subsection{Employee Engagement}

Managers and workers alike have increased workloads as a result of the recession, often leading to stress and depression health-related issues, with $42 \%$ of managers reporting symptoms [23]. In 
order for management to address employee needs and retain talent during the post-recessionary period, they must ensure a work-life balance, develop opportunities and communicate. Work-life balance may include options for flex-time and shared or reduced workloads during the postrecessionary period. This will improve engagement and avoid employees suffering from burn out. Career development opportunities should also be added to give employees the ability to improve their knowledge through education or mentoring programs. An ongoing two-way communication between employees and managers is also critical with communication identifying the teamwork aspects, and organizational paths and objectives where the employees can make the greatest contribution to the organizational effort [20].

\subsection{Talent Development}

Top companies continually analyze employee data to improve competitive advantages, improve engagement, retention, and productivity. Existing talent is moved through established career paths and career plans. New talent is added through co-op programs, job rotation, and experienced talent acquisition. Employees are expected to advance through continuous educational development, and entry level and experienced talent should be continually added to supplement the overall talent pool. Methods to measure talent include key positions having two or more ready replacements, and employees have rotated into multiple department areas [25, 26].

\section{CONCULSION AND FUTURE DIRECTIONS}

In keeping with the focus of The International Journal of Managing Information Technology (IJMIT), best practices for managing IT innovation are presented to utilize strategic IT in recessionary and post-recessionary periods. A new set of service and staffing model perspectives are presented for management of IT innovation. Focusing on continued innovation and allocating staffing to provide value-added IT services is key to sustained growth and successful transition during and after recessionary periods. Organizations should identify current allocation rates, and set targets for future allocation rates targeted towards innovation. This will ensure successful transition into the post-recessionary business environment. In addition organizations can utilize the IT service and staffing allocation matrix for innovation to identify gaps in their current strategy and focus. For example, through a self-assessment, organizations can identify which best practice components are currently being staffed and shift resources or initiatives to focus on items

which best align with core business competencies. Management implications are discussed for re-engaging employees to ensure talent is successfully managed and positioned for successful innovation. Future directions include expanding identified best practices and establishing longitudinal studies amongst several industries and organizations to measure the effects of innovation before and after recessionary periods.

\section{REFERENCES}

[1] C. U. Staff, "Are IT Staffing Issues Delaying New Technology?," in CIOUpdate, 2010.

[2] G. Baker, "How to Align IT with Income," in CIOUpdate, 2010.

[3] S. Williams, Williams, Nancy, The Profit Impact of Business Intelligence, 2007.

[4] B. T. Horowitz, "5 Ways to Keep Innovation Alive In a Recession," in CIOUpdate, 2008.

[5] J. M. Woodside, "Managing Information Technology Innovation: Recessionary Service and Staffing Model Perspectives," presented at International Technology Management Conference, 2011.

[6] M. Wade, Hulland, John, "Review: The Resource-Based View and Information Systems Research: Review, Extension and Suggestions for Future Research," MIS Quarterly, vol. 28, pp. 107-142, 2004. 
[7] A. Martensson, "A resource allocation matrix approach to IT management," Information Technology Management, vol. 7, pp. 21-34, 2006.

[8] E. Hubbert, O'Donnell, Glenn, "Service Catalog - Your Prerequisite For Effective IT Service Management," 2009.

[9] R. Leopoldi, "IT Services Management: A Description of a Service Catalog," 2002.

[10] G. Riempp, Gieffers-Ankel, Stephan, "Application portfolio management: a decision-oriented view of enterprise architecture," ISeB, 2007.

[11] Computer Sciences Corporation, "Application Portfolio Management - Business Agility," 2010.

[12] T. Wailgum, "Why Your Enterprise App Portfolio Strategy Needs a Reality Check," in CIO, 2010.

[13] T. Wailgum, "Cloud Computing: It's No Y2K Bonanza for IT Consulting Industry," in CIO, 2010.

[14] HP, "Sustainability," 2011.

[15] K. Walsh, "Environmentally Sustainable IT Definition and Solutions," in CIO, 2007.

[16] K. Gill, O'Brien, Karen, "The CIO and the sustainable enterprise: leader or led?," IBM 2010.

[17] P. D. Kretkowski, "The 15 Percent Solution," Wired, Ed., 1998.

[18] Google, "The engineer's life at Google," 2010.

[19] S. Berkun, "Thoughts on Google's 20\% time," 2008.

[20] D. Schroeder-Saulnier, "Reengaging Employees in a Post-Recession World," Best Practices in HR, 2010.

[21] H. Bradford, "U.S. Annual Income Fell More During Recovery Than Recession," in The Huffington Post, 2012.

[22] J. R. Ryan, "Keeping Employees Happy in a Post-Recession World," in Business Week, 2010.

[23] D. Woods, "Post-recession Authoritarian Management Style Depresses Job Satisfaction," in HR Magazine, 2012.

[24] B. Amble, "Welcome to the Post-Recession Reality," in Management Issues, 2010.

[25] T. H. Davenport, Harris, Jeanne, Shapiro, Jeremy, "Competing on Talent Analytics," Harvard Business Review, 2010.

[26] J. A. Conger, Fulmer, Robert M., "Developing Your Leadership Pipeline," Harvard Business Review, 2003. 